\title{
Vorwort
}

\section{Nosratollah Rastegar}

Vor etwas mehr als eintausend Jahren vollendete Abu'l Qasem mit dem Künstlernamen Firdausi nach fünfunddreißigjähriger ununterbrochener Arbeit sein monumentales poetisches Erzählwerk Schahname, ein Werk, das im Laufe seiner Rezeptions- und Wirkungsgeschichte wie kein anderes Werk der iranischen Dichtkunst immer wieder, und ganz besonders seit dem 19. Jahrhundert, das kulturgeschichtliche Verständnis der Iraner vom antiken Iran geprägt hat. Es ist so zu dem „iranischen Nationalepos“ geworden, als das es bereits vor mehr als 100 Jahren der Orientalist Theodor Nöldeke bezeichnete. ${ }^{1}$ Es war nach Jahrzehnte langer Arbeit, um mit Worten Heinrich Heines zu sprechen, ein Märchen aus alten Zeiten in poetischem Hochglanz entstanden, das keinem Persischsprachigen mehr aus dem Sinne gehen sollte:

S 60 basī ranğ burdam darīn sāl sī 'ağam zinda kardam ba-dīn pārsī

Viel Mühsal habe ich in diesen dreißig Jahren ertragen (und) habe die Iranier ('ağam) mit diesem Persisch (wieder) zum Leben erweckt ${ }^{2}$

1 Theodor Nöldeke: Das Iranische Nationalepos, in: Grundriss der Iranischen Philologie, Straßburg 1896-1904, Bd. 2, 130-211. Persische Übersetzung: Hamāsa-i millīi İrān / Tỉūdūr Nūldika. Tarğuma-i Buzurg 'Alawī. Bā muqaddama bi-qalam: Sa īd Nafīsī, Našr-i Ğâmî, Teheran Našr-i Sipihr 1369 [1990].

2 Übersetzung von Helmhart Kanus-Credé: Das Königsbuch. Augustin, Glückstadt Buch 1-9: 2002-3, ISBN 3-87030-127-9, ISBN 3-87030-128-7, ISBN 3-87030-130-9. 
Firdausi, der Verfasser des „Buchs der Könige“

Über Firdausis eigentlichen Namen oder über die Identität seiner Familie ist uns nichts Sicheres bekannt, außer den wenigen autobiographischen Informationen, die er im Text des Schahname hier und da eingestreut hat.

Abu'l Qasem Mansur (als Name ist statt Mansur auch Hasan oder Ahmmad überliefert), kurz Firdausi („der Paradiesische“), wurde zwischen 932 und 940 n. Chr. wohl im Dorf Wāž oder Bāž im Bezirk Tūs in der Nähe der heutigen Stadt Mashhad im Nordosten Irans als Sohn einer wohlhabenden Landadelsfamilie (dihqān) geboren. Er starb um 1020 n. Chr. in seiner Geburtsstadt Tūs und ist dort begraben.

Anfangs war Firdausi finanziell unabhängig und konnte sich schon sehr früh in der Kulturstadt Tūs ein großes Wissen über die Geschichte und Legenden des alten Iran, aber auch über die noch junge Tradition der neupersischen Dichtung aneignen, weshalb man ihn um 975 einlud, das mittelpersische $X^{v}$ adāynāmag („Königsbuch“) aus der spätsasanidischen Zeit in poetischer Form ins Neupersische zu übertragen. Diese Übertragung aber hatte eine Vorgeschichte, über die auch Firdausi Bescheid wusste.

Vor ihm hatte nämlich ein Abu'l Mu'ayyad aus Balkh eine neupersische prosaische Teil-Übersetzung des $X^{v}$ adāynāmag unternommen. Nach Abu'l Mu'ayyad entstand eine ebenfalls fragmentarische Übersetzung durch den Dichter Abū Manșūr Muḥammad b. Aḥmad Daqīīi, der vor seinem jähen Tod nur die ersten 1000 Verse aus dem 15. Buch Guštāsp in lyrischer Form ins Neupersische übertragen konnte. Diese 1000 Verse hat Firdausi unverändert in sein Werk integriert. Vor Daqīīi gab es bereits eine erste arabische, allerdings zusammenfassende Übersetzung von Abū Muhammad 'Abd Allāh Rūzbih ibn Dādūya, bekannt als Ibn al-Muqaffac (ca. 721-757 n. Chr.). Leider sind weder das genannte mittelpersische $X^{v}$ adāynāmag noch die arabische Übersetzung von Ibn al-Muqaffa ${ }^{c}$ oder die neupersische Prosaübersetzung 
des Abu'l Mu'ayyad erhalten geblieben. Insofern stellt das Schahname Firdausis innerhalb der iranischen epischen Überlieferung das einzig erhalten gebliebene neupersische poetische Erzählwerk über den antiken Iran dar.

Abgesehen von einer Reise nach Bagdad verbrachte Firdausi sein gesamtes Leben in Chorasan, wo er viel umherreiste, um dabei Material für seine Arbeit zu sammeln. Er genoss zunächst die Gunst von vier wohlhabenden Gönnern (Amīrak Abū Manșūr ibn 'Abd-ar-Razzāq, Statthalter von Tūs, nach dessen Tod 'Alī Dailamī Abū Dulaf sowie Abū Nașr Warrāq und schließlich Husain, Sohn von Qutaib). Durch die zunehmende Beschäftigung mit seinem Lebenswerk geriet Firdausi jedoch allmählich in finanzielle Not. Er wollte sich notgedrungen unter den Schutz des damals mächtigsten Herrschers in der östlichen islamischen Welt, Sulțān Maḥmūd von Ghazna, stellen. So reiste er in seinem 65. Lebensjahr nach Ghazna (im Osten des heutigen Afghanistan), um dem Sulțān sein Werk vorzulegen. Dieser hatte zwar zahlreiche Künstler und Literaten an seinem Hof in Ghazna versammelt, galt selbst aber als wenig kunstsinnig. Jedenfalls schenkte er dem Werk Firdausis kaum Beachtung. Firdausi beklagte sich, Maḥmūd habe es nicht einmal eines Blickes gewürdigt. Der eigentliche Grund für die Ablehnung des Werkes lag wohl im mangelnden literarischen Verständnis des Herrschers, aber auch in den religiösen Differenzen des orthodox sunnitischen Mahmūd mit dem sich offenbar zur Schica bekennenden Firdausi. Aus diesem Grunde soll Firdausi - einer anderen Legende zufolge - nach seinem Tod auch die Beisetzung auf einem muslimischen Friedhof verweigert worden sein.

\section{Das „Buch der Könige“: Aufbau und Charakter des Werkes}

Der Schahnametext beginnt mit der Einleitung Firdausis (ca. 237 Doppelverse), gefolgt von 50 überlieferten Königsbüchern (52.000 -55.000 Doppelverse), die man inhaltlich einteilen kann in a) prähistorischer, mythischer Teil (Bücher 1-13), b) halbhistorischer Teil 
(Bücher 14-19) und c) historischer Teil (Bücher 20-50). Dieser letztere Textteil, den Pollak als Vorlage für seine Übersetzung nahm, umfasst die überlieferte Geschichte der Herrschaft Alexanders über den Iran (331-323 v. Chr.), die Herrschaftsperiode der Parther-Arsakiden (247 v. Chr.-226 n. Chr.) und die umfangreiche Geschichte der Sasaniden (226-651 n. Chr.), schließend mit einer in ihrer Echtheit und ihrem Umfang strittigen Satire gegen den ghaznavidischen Herrscher, Sulțān Maḥmūd (reg. 999 bis 1030 n. Chr.).

Dieses „glorreiche Gedicht“ (nāmvar nāme), wie sein Verfasser es nennt, ${ }^{3}$ ist von der Textsorte her eine Matnawī, also eine dichterische Form, in der die einzelnen Halbverse nach dem Schema AA, BB usw. gereimt sind. Sie eignet sich besonders für lange epische Gedichte. Der gesamte Schahnametext ist im Metrum $\mathrm{mu}^{-}$ taqārib geschrieben. In diesem dem bacchischen Vers ähnlichen Versmaß folgt jeder der beiden symmetrisch gebauten Halbverse dem rhythmischen Schema $\cup--\cup--\cup--\cup-$ (gelegentlich mit leichten Abweichungen).

Über den Umfang des Schahname herrscht in der Forschung keine einheitliche Meinung. Nach einigen - allerdings in der Forschung strittigen - Versen am Ende des Schahname soll es 60.000 Doppelverse umfassen (be šiš bēvar abyātaš āmad šumār: „Seine Doppelverse zählen sechsmal zehntausend“), aber die meisten erhalten gebliebenen Handschriften bieten zwischen 50.000 bis ca. 56.000 Doppelverse. ${ }^{4}$

3 ču ìn nāmvar nāme āmad bi bun,

Wie ans Ende gelangt mein glorreich Gedicht, zi man rōy-i kišvar šuvad pur sahun

bin ich's, von dem das ganze Land spricht

namīram az ìn pas ki man zende-am,

Ich sterbe fortan nicht, denn ich bin lebendig,

ki tuhm-i sahuun rā parākande-am.

die Samen der Worte verstreut' ich beständig.

har ān kas ki dārad huš o rāy o dīn,

Wer Verstand hat und Glauben und Wissen erworben,

pas az marg bar man konad āfarīn

der wird mich segnen, wenn ich verstorben. (übers. R.A. Pollak)

4 Eine Londoner Handschrift beinhaltet dagegen sogar mehr als 70.000 
Nicht nur in der Einleitung und in der Satire, sondern auch in den 50 überlieferten Königsbüchern finden wir immer wieder längere Abschnitte, die Firdausis eigene Meinung und Wertung der überlieferten Geschichten sowie seine philosophischen, politischen und ethischen Auffassungen wiedergeben, sodass das Schahname keineswegs als eine bloße Wiedergabe der vorislamischen Überlieferungen gelten kann. Gerade seine lehrhaften Kommentare und pointierten Stellungnahmen unterstreichen die Bedeutung dieses einzigartigen poetischen Erzählwerkes.

Mit der vorliegenden Übersetzung Robert Adam Pollaks wird der umfangreiche historische Teil des epischen Meisterwerkes Firdausis (Bücher 20-50) erstmalig den deutschsprachigen Interessenten in poetischer Form zugänglich gemacht. Florian Schwarz hat in seiner Einleitung zu dieser Ausgabe dankenswerterweise die Biographie Pollaks rekonstruiert, so auch an Hand seiner Tagebücher die Entstehungszeit der hier vorgelegten Übersetzung Pollaks (1948-1952/53).

Allerdings hat es außer Pollaks Werk weitere deutsche Übersetzungen aus den mythischen und den halbhistorischen Teilen des Schahname gegeben. ${ }^{5}$ Zwar fehlt es immer noch an einer deutschen Gesamtübersetzung des Schahname, aber mit den 2010 aus dem Nachlass Friedrich Rückerts durch E.A. Bayer herausgegebenen Übersetzungen der Bücher 1-26 und dem jetzt vorliegenden Text Pollaks (Bücher 20-50) sind nunmehr die Grundsteine für eine vollständige deutsche Ausgabe gelegt worden, die neben Rückerts ${ }^{6}$ und Pollaks poetischen Übersetzungen auch die poeti-

Doppelverse, da sie auch Texte anderer im Umkreis des Schahname liegender Kleinepen wie Kok-e Kōhzād, Barzūnāme etc. einschließt. Vgl. Add. 21,103 (Rieu II, p. 533), Or. 11.842 u. 11.843 (Meredith Owens: Handlist of Persian manuscripts, London 1968).

5 Für einige deutsche Übersetzungen siehe: İraj Afshār: Ketābshenāsī-ye Ferdousī va Shahname („Bibliography on Firdowsi and Shahname“), Miras Maktoob, Teheran 1390 (2010/11) sowie: <https://de.wikipedia.org/wiki/Sch\%C4\%81hn\%C4\%81me\#Deutsch>

6 Friedrich Rückert: Firdosi's Königsbuch (Schahname). Aus dem Nachlass herausgegeben. Vol. I: Sage I-XIII. Berlin 1890; Vol. II: Sage XV-XIX, Berlin 
sche Übertragung Adolf Friedrich Graf von Schacks Heldensagen des Firdusi (1851) ${ }^{7}$ berücksichtigen könnte.

Dass die vorliegende Ausgabe ermöglicht wurde, verdanken wir dem Einsatz und der Unterstützung mehrerer Kolleginnen, Kollegen und Institutionen, und vor allem Robert Patzner, Enkel von Robert Adam Pollak, dem wir für die Überlassung des vierbändigen Typoskripts und der Publikationsrechte an das Institut für Iranistik der Österreichischen Akademie der Wissenschaften zu großem Dank verpflichtet sind. Mein Dank gilt auch der Österreichischen Akademie der Wissenschaften, die alle zum Druck erforderlichen Rechte an diesem Werk durch den Lizenzvertrag vom 14.3.2016 an mich übertrug.

Ich schließe mich den weiteren Danksagungen von Florian Schwarz vorbehaltlos an, möchte aber an dieser Stelle zunächst einmal ihm selbst danken für seinen umfassenden persönlichen Einsatz bei diesem Projekt. Mein Dank gilt ebenso seinen Vorgängern als Leiter der Kommission (seit 2002 Institut) für Iranistik, Jochem Schindler $(\dagger)$, Heiner Eichner und Bert G. Fragner, für die Jahrzehnte lange Betreuung und Unterstützung meiner Arbeit seit 1996. Auch meinem Sohn Keyvan Rastegar und meiner Schwiegertochter Katharina Rastegar, die in den letzten 7 Jahren mich und mein Schāhnāme-Projekt juristisch bestens betreut haben, danke ich ganz herzlich. $\mathrm{Zu}$ besonderem Dank verpflichtet bin ich dem Klaus Schwarz Verlag und seinem Geschäftsführer Gerd Winkelhane und besonders seinem Mitarbeiter Henrik Jeep für die hervorragende Betreuung bei der Vorbereitung des vorliegenden Textes zum Druck und für die sorgfältige und qualitätsvolle Herstellung der nun vorliegenden vier Bände.

1894; Vol. III: Sage XX-XXVI, Berlin 1895. Neuausgabe 3 Bde., epubli, Berlin 2010

7 Adolf Friedrich Graf von Schack: Heldensagen des Firdusi. Zum ersten Male metrisch aus dem Persischen übersetzt nebst einer Einleitung über das Iranische Epos. Berlin, Wilhelm Hertz, 1851, 1865, 2. Aufl. 